\title{
Antithyroid Drug Therapy for Graves' Hyperthyroidism: Is Long-Term Administration of a Small Maintenance Dose Necessary?
}

\author{
JUNiChi TAJIRI, Shiro NOGUCHI, Mitsuo MORITA, \\ MASAAKI TAMARU, AND NOBUO MURAKAMI \\ Noguchi Thyroid Clinic and Hospital Foundation, \\ Oita 874, Japan
}

\begin{abstract}
This retrospective study serves as an inquiry into the common practice of long-term administration of small maintenance doses of either methyl-mercaptoimidazole (MMI) or propylthiouracil (PTU) to Graves' hyperthyroid patients who became euthyroid with primary large doses of the same drugs.

One hundred and two patients with Graves' hyperthyroidism treated with antithyroid drug (ATD) were studied. Sixty-one were treated with conventional long term therapy and 41 were treated with short-term therapy. Small maintenance doses of ATDs were not administered to the short-term therapy patients. The duration of long-term therapy was $28.6 \pm 20.2$ months (from 12 to 48 months) and that of short-term therapy was $8.4 \pm 1.8$ months (from 5 to 11 ). Post therapy and follow-up observation continued for 19.0 \pm 2.7 months (16-25 months) in both long-term and short-term patients. Of the 61 long-term therapy patients, 20 were relapsed and $41(67.2 \%)$ continue to remain in remission. So too, of the 41 short-term therapy patients, 14 relapsed and $27(65.9 \%)$ still remain in remission. There was no statistical difference between the long-term and short-term therapy group in age, sex, duration of symptoms before diagnosis, antithyroid antibodies, radioactive iodine uptake, free thyroid hormone levels or goiter size before treatment or in TBII levels at cessation of ATD.

It is concluded that 'short-term ATD therapy' without a maintenance dose is sufficient and saves several months of the patient's and clinician's time.

(Endocrinol Japon 38: 223-227, 1991)
\end{abstract}

THAT GRAVES' thyrotoxic patients can be treated with antithyroid drugs (ATDs) is well known, but the duration of ATD treatment is one of the important factors which influence the outcome of ATD treatment $[4,6,10]$. It is generally said that ATD therapy for more than two years results in a higher remission rate than short-term therapy $[4$, 10]. However, longer courses of therapy are associated with problems related to compliance and regular clinic supervision.

Greer et al. [6] reported that the remission rate was as good in patients who discontinued ATDs soon after becoming euthyroid as it was in patients

Received: January 8, 1991

Accepted: March 15, 1991

Correspondence to: Dr. Junichi TAJIRI, Noguchi Thyroid Clinic and Hospital Foundation, 6-33 Noguchi Naka-Machi, Beppu, Oita 874 Japan. who discontinued ATDs only after a longer period of one year or more. Provided that remission with short-term ATD comes with the same frequency and long lasting result as conventional treatment, this would represent a considerable saving in patient's and clinician's time. In addition, those who relapse could be referred at an earlier stage for other forms of therapy. In short-term treatment previously reported, an initial dose of ATD (MMI $30 \mathrm{mg}$ daily or PTU $300 \mathrm{mg}$ daily) was continued until the patients became biochemically euthyroid, at which point ATDs were immediately stopped. Therefore, although the duration of ATD was short-term (3-4 months), the remission rate was low $(30-40 \%)[6,9]$.

In this study conducted at the Noguchi Thyroid Clinic, ATDs were gradually reduced in the same way as in conventional therapy; and when the 
patients became euthyroid with normal serum TSH levels on a daily dose of $5 \mathrm{mg}$ MMI or $50 \mathrm{mg}$ PTU for 2 months, and ATDs were immediately discontinued without the administration of a small maintenance dose. In Japan, conventional therapy recommended that a small maintenance dose of ATDs, either MMI 5-10 mg daily or PTU 50-100 mg daily, be continued for at least 6 to 12 months. Our treatment method required from 5 to 11 months; so, in this study, we call this treatment short-term therapy.

The necessity for long term administration (six months to one year) of a small maintenance dose of ATDs in patients who became euthyroid with a large primary dose of the same drug remains a questionable issue. Therefore, the aim of this study is to compare the remission rate for shortterm therapy without a small maintenance dose of ATDs to the remission rate for conventional long-term therapy with a small maintenance dose of ATDs.

\section{Patients and Methods}

From January 1984 to June 1988, one hundred and two patients in the area of Oita prefecture with Graves' hyperthyroidism (21 males and 81 females, aged $40.5 \pm 15.7 \mathrm{yr}$ ) were treated with either MMI $(n=92)$ or PTU $(n=10)$. The diagnosis of Graves' disease was based on diffuse goiter, increased serum thyroid hormones, a suppressed TSH level (less than $0.3 \mu \mathrm{U} / \mathrm{ml}$ ) and increased thyroidal 131-I uptake. Goiter size was estimated by palpation. Those who had previous ATD treatment for Graves' disease were excluded. Thyroidectomy was recommended for the patients with a large goiter. Radioiodine therapy was the first choice for older patients, and those having small goiters were particularly recommended for ATD therapy. In the first part of this experiment, the patients with hyperthyroidism of Graves' disease were treated initially with $30 \mathrm{mg}$ MMI or 300 mg PTU daily; the dose was reduced gradually depending on the serum concentrations of free $\mathrm{T} 4$ (FT4), free T3 (FT3) and TSH. The maintenance dose (the minimal dose necessary to maintain euthyroidism) was administered for at least 6 months. The doses were administered to maintain serum FT4 ranging from 0.7 to $1.0 \mathrm{ng} / \mathrm{d} l$, serum FT3 ranging from 2.7 to $4.0 \mathrm{pg} / \mathrm{m} l$ and TSH levels less than $3.5 \mu \mathrm{U} / \mathrm{m} l$ (normal range $0.3-3.5 \mu \mathrm{U} / \mathrm{m} l$ ). When serum TSH levels were normal, ATDs were discontinued. In the second part of this study, the experimental procedures were the same as in the first part of the experiment, except that the maintenance dose of ATDs was adminsitered for 2 months. When serum TSH levels remained normal, the treatment was discontinued.

The prescriptions read, once a day in the morning when the daily dose was $5 \mathrm{mg}$ of MMI or $50 \mathrm{mg}$ of PTU; twice a day at $12 \mathrm{~h}$ intervals when the dose was $10 \mathrm{mg}$ and $20 \mathrm{mg}$ of MMI or $100 \mathrm{mg}$ and $200 \mathrm{mg}$ of PTU, and three times daily at $8 \mathrm{~h}$ intervals when doses were $15 \mathrm{mg}$ and $30 \mathrm{mg}$ of MMI or $150 \mathrm{mg}$ and $300 \mathrm{mg}$ of PTU.

Patients were followed up at intervals of one to three months for at least 1 year after stopping ATDs and later at intervals of six months. Sixteen patients were treated with PTU because of allergy to MMI. Beta-blockers were used in some patients.

Relapse of hyperthyroidism was diagnosed by increased thyroid hormone levels and obvious clinical hyperthyroidism.

FT4 and FT3 were measured with commercially available RIA kits (Amerlex FT4 and FT3, from the Radiochemical Center, Amersham International, Amersham, England). TSH was measured by high sensitive assay (immunoradiometric assay (IRMA) Daiichi Radioisotope, Japan). TBII was measured with a Smith's kit (Travenol clinical assay, Cambridge, MA, USA). Microsomal antibody (MCHA) and thyroglobulin antibody (TGHA) were measured by hemagglutinination methods. The normal ranges in our clinic were $0.7-1.8 \mathrm{ng} / \mathrm{d} l$ for FT4, 2.7-5.9 $\mathrm{pg} / \mathrm{ml}$ for FT3, $0.3-3.5 \mu \mathrm{U} / \mathrm{ml}$ for TSH, $10 \%<$ for TBII and $1: 10<$ for MCHA and TGHA.

Student's $t$-test and Chi square test were used for statistical analysis. Values were expressed as the mean \pm standard deviation (SD).

\section{Results}

Of 102 patients with Graves' hyperthyroidism who could be followed up, 61 with conventional long-term therapy and 41 with short-term therapy had normal serum TSH levels at cessation of ATDs. Nine patients undergoing long-term therapy and eight patients under short-term therapy whose serum TSH levels were suppressed (less 
Table 1. Clinical profiles of 102 patients with long-term or short-term ATD therapy

\begin{tabular}{|c|c|c|c|}
\hline & Long-term therapy & Short-term therapy & p-value \\
\hline No. of patients & 61 & 41 & \\
\hline Duration of ATD (months) & $28.6 \pm 20.2$ & $8.4 \pm 1.8$ & $\mathrm{p}<0.01$ \\
\hline Age (yr) & $38.9 \pm 16.3$ & $43.0 \pm 15.0$ & N.S. \\
\hline Sex (male: female) & $12: 49$ & $9: 32$ & N.S. \\
\hline $\begin{array}{l}\text { Duration of symptoms } \\
\text { before diagnosis (months) }\end{array}$ & $3.0 \pm 2.5$ & $2.5 \pm 2.0$ & N.S. \\
\hline $\begin{array}{l}\text { Incidence of positive } \\
\text { MCHA }\end{array}$ & $46 / 61$ & $30 / 41$ & N.S. \\
\hline $\begin{array}{l}\text { Incidence of positive } \\
\text { TGHA }\end{array}$ & $22 / 61$ & $12 / 41$ & N.S. \\
\hline 131-I uptake $(\%, 24 \mathrm{~h})$ & $55.3 \pm 15.0$ & $57.6 \pm 14.6$ & N.S. \\
\hline Free T3 $(\mathrm{pg} / \mathrm{m} l)$ & $13.5 \pm 4.1$ & $14.1 \pm 6.0$ & N.S. \\
\hline Free T4 $(\mathrm{ng} / \mathrm{d} l)$ & $4.5 \pm 1.7$ & $4.7 \pm 2.1$ & N.S. \\
\hline Goiter size (g) & $31.7 \pm 6.5$ & $30.2 \pm 6.6$ & N.S. \\
\hline Incidence of $>40 \mathrm{~g}$ & $12 / 61$ & $6 / 41$ & N.S. \\
\hline TBII at cessation of ATD (\%) & $15.9 \pm 19.7$ & $15.4 \pm 19.3$ & N.S. \\
\hline $\begin{array}{l}\text { Incidence of positive } \\
\text { TBII at cessation of } \\
\text { ATD }\end{array}$ & $18 / 61$ & $12 / 41$ & N.S. \\
\hline
\end{tabular}

ATD, antithyroid drug; MCHA, microsomal antibody; TGHA, thyroglobulin antibody; TBII, thyrotropin-binding-inhibitor-immunoglobulin.

than $0.3 \mu \mathrm{U} / \mathrm{m} l)$ at the cessation of ATDs were excluded from this study. Four patients under long-term therapy and 3 patients under shortterm therapy who were lost to follow up were also excluded from this study. As shown in the table, there was no difference between the long-term and short-term therapy groups in age, sex, duration of symptoms before diagnosis, antithyroid antibodies, radioactive iodine uptake, FT3, FT4 and goiter size before treatment or TBII levels at cessation of ATD. The duration of long-term therapy was $28.6+20.2$ months (from 12 to 48 months) and that of short-term therapy was $8.4 \pm 1.8$ months (from 5 to 11 months). The duration of follow-up after cessation of ATD was $19.0 \pm 2.7$ months (16-25) and did not differ between the short term therapy and long-term therapy groups. Forty-one of $61(67.2 \%)$ treated with long-term therapy have remained in remission. The remaining twenty patients relapsed $1-8$ months (3.5 \pm 2.1 months) after cessation of ATDs. Twenty-seven of $41(65.9 \%)$ treated with shortterm therapy have remained in remission. The remaining fourteen patients relapsed 2-11 months (4.1 \pm 2.8 months) after stopping ATDs. Eleven of 20 relapsed patients in long-term therapy and eight of 14 relapsed patients in short-term therapy had positive TBII at the cessation of ATD treatment (long-term therapy vs short termtherapy; N.S.). Patients who experienced relapse were treated with ATD $(n=15)$, surgery $(n=6)$ and radioactive iodine therapy $(n=13)$.

\section{Discussion}

It is difficult to determine whether a patient is in remission and if that remission is long lasting or merely temporary. Several tests have been recommended: return of T3 suppressibility [13] , return of response to TRH stimulation [5], serum thyroglobulin levels [11], thyroid stimulating antibody [14], thyrotropin-binding-inhibitor-immunoglobulin [2] and HLA typing [7]. However, none of these tests have proved to be capable of predicting the future course of the disease. 
Moreover, the tests are very expensive. Therefore, stopping ATD is thought to be the best way to determine whether the patient remains in remission or not.

We found that short-term therapy, in which ATDs were reduced in the same way as conventional therapy, and then discontinued without the administration of a small maintenance dose for 6 months, showed the same remission rate as the conventional long-term therapy. Our results suggest that early discontinuation of ATD saves several months in both patient's and physician's time. It has been commonly believed that one to two years of ATD therapy is usually necessary to induce a remission [4]. Indeed, Tamai et al. [10] reported a direct correlation between the remission rate and the duration of therapy, with remission rates of $31 \%$ after six months of therapy and $82 \%$ after two years. However, Greer et al. [6] and others [3] have reported that remission rates are similar (30 to $40 \%$ ) regardless of whether ATDs are given only until the patient is euthyroid (i.e., for two to six months) or whether they are administered for longer periods (i.e., for one to two years). Our present study suggests that a small maintenance dose over a long period may not be necessary in patients who have normal serum TSH levels when $5 \mathrm{mg}$ of MMI or $50 \mathrm{mg}$ of PTU daily has been administered for 2 months after achievement of euthyroidism with large amounts of ATD.

The overall remission rate determined from various reports ranges from 14 to 96 percent [6]. Although it is difficult to compare remission rates from different investigators because of differences in protocol and the patient population, it has been widely recognized that the rate of prolonged remission has been gradually reduced over the years [8]. Wartofsky et al. [12] proposed that an increase in dietary iodine might be responsible for the apparent decreased effectiveness of ATD, thereby resulting in a reduced remission rate and increased rate of relapse. Yet the results of our short-term therapy showed a higher remission rate than those of the usual short-term therapy reports.
While therapy was short term, our treatment was marked with a gradually reduced dose of ATDs and a slightly longer period of treatment. In previously reported short-term therapy, an initial large dose of ATD is administered and then immediately stopped when the patients become euthyroid biochemically [6] or when a serum high sensitive TSH level is detectable [9]. However in our short-term therapy, ATD is gradually reduced in the same way as conventional long-term therapy and when the patients become euthyroid with normal serum TSH levels after $5 \mathrm{mg}$ of MMI or 50 mg of PTU for two months, ATD is discontinued immediately without a small maintenance dose. The duration of therapy is slightly longer than the usual short-term therapy and a higher remission rate in our short-term therapy method may be attributed to this moderately longer period of therapy compared to the extreme approach of traditional short-term therapy.

This study is preliminary and retrospective. Because the two groups were temporally separated and chosen from a minor subset of all patients, selection bias may have influenced our results. Ideally, all patients available for antithyroid drug therapy should have been randomized between the two treatment groups.

In conclusion, this study suggests that a small maintenance dose of ATDs for at least 6 months might be unnecessary in patients who have normal serum TSH levels when $5 \mathrm{mg}$ of MMI or $50 \mathrm{mg}$ of PTU is administered daily for two months after the achievement of euthyroidism with large amounts of ATDs. It is concluded that 'short term therapy' without a maintenance dose is sufficient and saves several months of patient's and clinician's time.

\section{Acknowledgements}

We would like to thank Linda Kawabata for reading and correcting the manuscript.

\section{References}

1. Alexander WD, Kerr DJ, Ferguson MM (1984) First-line test of thyroid function. Lancet 2: 647 .

2. Bliddal H, Kirkegaard C, Kaj Siersbæk-Nielsen K, Friis T (1981) Prognostic value of thyrotrophin binding inhibiting immunoglobulins (TBII) in long-term antithyroid treatment, 131-I therapy given in combination with carbimazole and in euthyroid ophthalmopathy. Acta Endocrinol 98: 
364-369.

3. Bouma DJ, Kammer H, Greer MA (1982) Followup comparison of short-term versus 1-year antithyroid drug therapy for the thyrotoxicosis of Graves' disease. J Clin Endocrinol Metab 55: 1138-1142.

4. Cooper DS (1984) Antithyroid drugs. N Engl J Med 311: 1353-1362.

5. Dahlberg PA, Karlsson FA, Jansson R, Wide L (1985) Thyrotropin-releasing hormone testing during antithyroid drug treatment of Graves' disease as an indication of remission. $J$ Clin Endocrinol Metab 61: 1100-1104.

6. Greer MA, Kammer H, Bouma DJ (1977) Shortterm antithyroid drug therapy for the thyrotoxicosis of Graves' disease. N Engl J Med 297: $173-176$.

7. Irvine WJ, Gray RS, Morris PJ, Ting A (1977). Correlation of HLA and thyroid antibodies with clinical course of thyrotoxicosis treated with antithyroid drugs. Lancet 20: 898-900.

8. Solomon DH (1986) Treatment of Graves' hyperthyroidism. In: Ingbar SH and Braverman LE (ed) The Thyroid. 5th ed, Philadelphia, Lippincott Company, p 992.

9. Takamatsu J, Ikegami Y, Sakane S, Takeda K, Kitaoka H, Kuma K (1989) Prediction of the outcome of hyperthyroidism due to Graves' disease before antithyroid drug therapy is embarked. The Fourth Asia and Oceania Thyroid Association Meeting, II-2-3, Seoul.

10. Tamai H, Nakagawa $T$, Fukino O, Ohsako N, Shinzato R, Suematsu H, Kuma K, Matsuzuka F, Nagataki S (1980) Thionamide Therapy in Graves' disease: Relation of relapse rate to duration of therapy. Ann Intern Med 92: 488-490.

11. Uller RP, Van Herle AJ (1978) Effect of therapy on serum thyroglobulin levels in patients with Graves' disease. J Clin Endocrinol Metab 46: 747-755.

12. Wartofsky L (1973) Low remission after therapy for Graves' disease: Possible relation of dietary iodine with antithyroid therapy results. JAMA 226 : 1083-1088.

13. Yamada T, Koizumi Y, Sato A, Hashizume K, Aizawa T, Takasu N, Nagata H (1984) Reappraisal of the 3,5,3'-triiodothyronine-suppression test in the prediction of long term outcome of antithyroid drug therapy in patients with hyperthyroid Graves' disease. J Clin Endocrinol Metab 58: 676-680.

14. Zakarija M, McKenzie JM, Bonavoc K (1980) Clinical significance of assay of thyroid-stimulating antibody in Graves' disease. Ann Intern Med 93: 28-32. 